\title{
The Information Process and the Labour Process in the Information Age
}

\author{
Jaime F. Cárdenas-García*, Bruno Soria de Mesa** and Diego Romero \\ Castro*** $^{* *}$
}

*University of Maryland - Baltimore County, Baltimore, USA, ifcg@umbc.edu

${ }^{* *}$ Escuela Superior Politécnica del Chimborazo, Riobamba, Ecuador, bruno.soria@espoch.edu.ec

***Universidad de Guayaquil, Guayaquil,Ecuador, diego.romeroc@ug.edu.ec

\begin{abstract}
This paper examines how information fundamentally influences the labour process in the information age. The process of becoming human in the labour process brings to the fore the notion of information and our dialectical interactions with our natural environment as organisms-in-the-environment. These insights lead the authors to posit that information/ideas are material. Information/ideas are not ethereal/immaterial, as is commonly believed, which does not negate that information/ideas may be abstract. Taking a fundamental approach serves to discard the concept of immaterial labour and products to posit an undeniable materialist basis for the labour theory of value. More importantly, it serves to point to the immanence of information and labour in the labour theory of value.
\end{abstract}

Keywords: Digital Labour, Critical Theory, Labour Theory of Value, Commodity, Information, Ideas, Material, Physical, Immaterial, Science of Information, Distributed Cognition, Dialectics, Communication, Shannon Information, Distilled Information

Acknowledgement: The authors would like to acknowledge the reviewers as well as the editor for their comments and suggestions, which have helped to improve the content of this paper.

\section{Introduction}

Twentieth-century capitalism evolved from the industrial age to the information age (Castells 2009). The industrial age was characterised by the production of manufactured goods and services. The information age evolved to incorporate information as an important element, if not the major element, in the production process. The information age requires information not only as an input to its evolution and development, but as an output that can become an input in an ever-evolving pattern of development. Information and Communication Technologies (ICTs) "such as computers, TV, radio, newspapers, books, recorded films, recorded music, language, etc., organise (i.e. store, process, transport, analyse, transform, create) information and communication" (Fuchs 2016, 60). ICTs typical of the information age encompass products that are fundamentally digital. The centrality of information requires a knowledge of the nature of information and how it affects the development of the information age. It is exactly this that is the Achilles heel of interpreting the functioning of the information age, especially since one of the main parameters is that of labour: but, specifically, labour that relies on information as a raw material, 
and also produces information as the product of its informational processes, reused in an endless process.

The proliferation of digital ICTs includes hardware and software components that have become ubiquitous in our daily lives. The proliferation of digital television, portable computers and digital tablets complements the associated apps that access the Internet: email, Twitter, Facebook, Dropbox, YouTube and Pandora. All of these have become indispensable, everyday-use consumer articles. Associated with the proliferation of digital media is all of the infrastructure required to sustain its production and its consumption: from the mining and processing of raw materials, to the manufacture of products, to the needed fundamental research that supports the industrial-scale production and assembly of components, as well as the worldwide distribution and marketing required to convert digital products into necessary items for daily living.

This paper seeks to ascertain that, fundamentally, information and ideas are material; and to explore the implications of this perspective. The essence of dealing with the body, the brain and digital machines is the same, i.e., their workings are all material in nature. This is also the context under which so-called digital labour falls. It is not difficult to surmise that 'information' is part of digital labour. What is hardly ever mentioned is that 'information' is not as transparent a concept as it is made out to be. There is no consensus on what information is, or even how it relates to "ideas" (Hofkirchner 2013a). Therefore, if digital labour is to be explained in all its dimensions, information has to be conceptually explained to take full advantage of any applicable derived implications. In short, the goal of this paper is to establish a material basis for all things digital, and, further and more importantly, to examine the larger implications and ramifications of doing so.

The paper is divided into four sections. First, a review of recent critical theory situates the arguments in this paper and argues for the centrality of information. Second, a definition of information that emphasises its dynamic nature is presented. Third, the role of humans as cognizing beings in a process of distributed cognition is shown to be central to information. Last, the immanent connection between labour and information is explored.

\section{Preliminaries}

This section briefly reviews autonomist Marxist critiques and digital labour countercritiques which lead to focusing on the centrality of information in the labour debate.

\subsection{Autonomist Marxist Critiques}

In an effort to conform to the developments of the information age, autonomist Marxist critiques of the relevancy of the law of value arose. This autonomist perspective advanced the notion of immaterial labour (Hardt and Negri 2000; Mosco 2009; Virno and Hardt 1996). In particular Lazzarato states:

[...] the concept of immaterial labor, which is defined as the labor that produces the informational and cultural content of the commodity. The concept of immaterial labor refers to two different aspects of labor. On the one hand, as regards the "informational content" of the commodity, it refers directly to the changes taking place in workers' labor processes in big companies in the industrial and 
tertiary sectors, where the skills involved in direct labor are increasingly skills involving cybernetics and computer control (and horizontal and vertical communication). On the other hand, as regards the activity that produces the "cultural content" of the commodity, immaterial labor involves a series of activities that are not normally recognized as "work" - in other words, the kinds of activities involved in defining and fixing cultural and artistic standards, fashions, tastes, consumer norms, and, more strategically, public opinion. (Lazzarato 1996, 133)

The "informational content" and "cultural content" of commodities seem to be the deciding factors in defining immaterial labour, though no understanding of information and how that impacts the cultural is proffered. Also, the discredited dualistic vision of "mental and manual labour" and related "immaterial labour" and "material labour", respectively, are the basis for making sense of the "great transformation" of capitalism that has occurred since the 1970s.

\subsection{Immaterial Labour Reborn}

New notions of Immaterial Labour have recently surfaced. ${ }^{1}$ Jappe (2013) suggests that labour may be material and immaterial, and considers computer science and those that work in the realm of computing to perform immaterial labour. This is especially true in post-Fordism, but Jappe argues against the notion of "immaterial labour" as "abstract labour" promoted by Negri (Hardt and Negri 2000). Jappe further asserts that the products resulting from computing add "homeopathic doses of human labour", drastically affecting the value of such products. Support for this argument is found in observing that once a software product has been invented it can be reproduced very cheaply and widely distributed without incurring significant labour costs (at the touch of a button, apparently). Of course, this has a detrimental effect on capitalism, due to the low doses of added value, and cannot but promote crises for capitalism.

While the continuing crises of capitalism are self-evident, it is not quite clear whether Jappe's assertions about immaterial labour have a basis in fact as regards computational labour. As we will argue, there is nothing immaterial about intellectual work, computational work or any other type of labour that is dependent on "the expenditure of human brain, nerves [...] and sense organs" (Marx 1976/1867, 55). Such intellectual exertions always lead to a material endpoint, such as software that is recorded in many different types of media. Making such a differentiation to discover immaterial labour and products is unnecessary and erroneous.

Jappe's assertions imply that the knowledge base on which such labour is sustained needs to keep improving, and such improvement takes place either by way of the individual worker continuing to enhance her technical and other education and capabilities on her own, or by so doing within the confines of her work environment. Also, once ideas are externalised, they may be recorded in digital media and used and reused by the capitalist in the same or new forms of presentation. Such labour does add value to the capitalist enterprise, sometimes in a significant way, as instanced by the multiple software empires that are alive and well.

1 https://marxismocritico.com/2016/10/03/trabajo-abstracto-o-trabajo-inmaterial/; accessed January 5, 2017. Similar views are expressed in Roos et al. (2016). 
The issue of adding "homeopathic doses of human labour" (Jappe 2013) when distributing software is not a well-thought-out matter. Let us go back in time and examine the example of books in physical form. As the capitalist printer and distributor of such items, I may have the desire to distribute in a massive way. What may dissuade me is not the costs of production, but the costs of advertising and distribution. I also need to ask myself what kind of book it is that I am distributing. Is it a novel geared towards a $6^{\text {th }}$ grade audience? Or is it a technical treatise that has a more limited audience?

The vagaries of software distribution are different but similarly complicated. I may get many users if I distribute ANGRY BIRDS ${ }^{\mathrm{TM}}$ as a free app; and I may recoup my expenses, requiring many and varied labour-intensive talents, to continue the maintenance and operation of my business by using web advertisements or selling an enhanced version of the game once I develop an addicted following and commodified audience (Smythe 1977; Fuchs 2012). Note that neither the hardware nor the software are of such low cost that the created capitalist enterprise is ethereal in nature. Also, the technical skill to achieve a successful project, as mundane as this might appear, is significant over the short- and the long-term. The other issue that lurks in the background, and which few consider, is the absorption of knowledge required on the part of the entrepreneur to pull something like this off. This is true at the front end and at the back end of an endeavour. If you are to continue to be successful, you have to invest in research and development (R\&D). This requires highly skilled programmers and other artists who are at the top of their game. Software development and distribution is a very competitive and capital-intensive enterprise.

In short, there are no such things as immaterial labour or products. Information and ideas have a concrete material embodiment, and human labour in all its expressions is material.

\subsection{Digital Labour}

Digital labour has taken centre stage as a counter-critique and a return to the more traditional perspective of Marxist theories of value. Its proliferation and importance is documented in entire treatises (Burston, Dyer-Witheford, and Hearn 2010; Fuchs 2014; 2016; Fuchs and Mosco 2012; Sandoval et al. 2014; Scholz 2013).

To begin to define and to examine digital labour we need to determine the basis for digital labour. Digital comes from the word digit (Latin for finger), associated with the quality of discreteness. The term is more recently associated with binary digits or bits. Bits are at the root of all present-day ICT applications in all areas of human society: communications, transportation, engineering, science, technology, computers, etc.

The beginnings of a realisation of the importance of digital labour occurred in a conference called 'Digital Labour: Workers, Authors, Citizens', held at the University of Western Ontario on October $16^{\text {th }}-18^{\text {th }}, 2009$ (Burston, Dyer-Witheford, and Hearn 2010). Its emphasis on digital labour tended towards the perspective and recognition that digital technology had become ubiquitous and that there was almost no aspect in our lives that was unaffected, the impact so pervasive that it was difficult to assess the ramifications:

To be sure the term 'digital' does not simply refer to digital machines and processes but to the entire political, social and economic context and infrastructure within which they 
have emerged. This is how we now live in a 'digital age'.

(lbid., 215)

The result is the recognition that we have become 'digital labourers' using a gamut of digital technologies, with great impact on most sectors of society. Indeed, it is suggested that the labour theory of value might be in need of critical revision, and new notions of analysis advanced.

What is not clear is how digital work bears any relationship to regular manual work: the back-breaking kind of work that still all too commonly is the antecedent to allowing digital work to become commonplace, especially in the major centres of capitalism. What is also unclear is the role that the human brain plays in this digital world of work, and even the relationship to speech and human experience.

A preliminary attempt by Fuchs and Mosco (2012) to begin answering some of these questions focuses on critical communications studies, returning to the more traditional perspective of Marxist theories of value. While the general discussion centres on how to apply a Marxist perspective to critical communications studies, the phrase 'digital labour' is almost ignored. Autonomist Marxist critiques still prioritise the analysis of labour.

A subsequent effort by Sandoval et al. (2014), still focusing on critical communications, explores 'digital labour' more fully. It endeavours to define, determine the dimensions of and identify the forms of 'digital labour' in an attempt to make sense of the future. But it does so in the context of a general conception of 'digital labour'. Digital labour is shown to be common to the hard physical labour inherent to mineral extraction, to the tediousness of manufacturing and assembly of digital artefacts, and to the creation of software or designs. As Sandoval et al. state: "They work under different conditions, such as slavery, wage labour, or freelancing. Yet they have in common that their labour is in different ways related to the production and use of digital technologies and that ICT companies profit from it" $(2014,487)$. In short, "digital labour includes both the creation of physical products and information that are required for the production and usage of digital technologies" (lbid., 493).

\subsection{Information is Central to the Discussion of Digital Labour}

In summary, what is important in the information age is the fundamental relationship that exists between information, ICT hardware and software, and labour. This is what has not previously been made fundamentally clear in critical communications studies, resulting in a theoretical vacuum that needs to be remedied.

An additional reason for this lack of interest may have been the development of the mathematical theory of communication by Shannon (1948; Shannon and Weaver 1949), which delimits the start of informational technology transformations that are currently in vogue whose impact even now is difficult to predict. These transformations led to the rapid development of information technology applications, digital technology and the digital revolution. They have had such a lasting impact that confusion exists as to whether communication is the same as information, and even whether the transmission of a message involves the transmission of meaning.

One of the key concepts related to information technology applications is that of information itself. Indeed, what is information? This is a question that researchers have found difficult to answer. No one is able to define information such that it has applicability to all fields of human inquiry, though everyone is able to recognise it (Hofkirchner 2013a). Additionally, the concept that ideas are not abstract but material in nature is not widely accepted. This might be the result of idealistic conceptions that 
are universal and prevalent in our time, especially because of the explosion of digital media, which has the potential to make what is real imaginary and what is imaginary real. Additionally, the classification of goods as tangible and intangible has made the distinction of information difficult to pinpoint as material or immaterial.

Another factor that may play a role in confusing the issue is that, in general, human work is seen as work that is congealed in commodities (or tools) as abstract human labour. ${ }^{2}$ The apparent intangibility of abstract labour may lead to difficulties in assessing its material basis. In particular, digital products can not only be saved in different physical form, but also manipulated to satisfy the requirements of clients. This enables a group-working structure, used for the creation of new products such as musical compositions, movies and videos, in which it does not matter where one group begins and another ends the work. These kinds of manipulations cannot be done with printed books or vinyl records: they are enabled by digital ICT applications. Human ideas in reality are material in nature, and we are able to manipulate them by putting them into machines for their processing and elaboration. This is the basis for reconsidering digital work and labour. Now we are not only capable of capturing the full range of human ideas and intangible work, but also of processing and manipulating them in new ways and forms. Now even individual ideas can be bought and sold, elaborated on and improved upon on an asynchronous basis, utilising all kinds of labour power, from every corner of the world, at any time of day or week.

A recent contribution to the debate (Zukerfeld 2017) adds the dimension of knowledge matter to that of physical matter in an effort to focus on the materiality of all aspects of this debate. This is in opposition to earlier attempts that consider immateriality as pertinent to seeking an explanation of how to incorporate information in explaining capitalism. The result is cognitive materialism, which attempts to reconcile all elements in this debate and to do so with an all-encompassing general theory. There are many fine points that are made in arguing for cognitive materialism, many of which are not pertinent to the current presentation. One that may be relevant is the differentiation that is made between knowledge and information. Zukerfeld limits the scope of information within the much broader concept of knowledge, and is very explicit in his reasoning. The presentation on information below does not require an explicit differentiation of knowledge, since information is viewed as dynamically, dialectically, spatially and temporally evolving for humans.

In short, work and labour related to digital ICTs are the new currency of capitalism that allows it an unequalled power over human labour - something that was not possible in the past. This is the new reality that Marxism has to consider.

\section{Information}

The perspective that "information is physical" is known (Landauer 1991). It may be ascribed both to nature and as a man-made product:

Information is not a disembodied abstract entity; it is always tied to a physical representation. It is represented by engraving on a stone tablet, a spin, a charge, a hole in a punched card, a mark on paper, or some other equivalent. This ties the handling of information to all the possibilities and restrictions of our real physical word, its

\footnotetext{
2 The pertinence of the difference between work and labour is discussed in Arendt (1998), Fuchs and Sevignani (2013) and Sandoval, Fuchs, Prodnik, Sevignani and Allmer (2014).
} 
laws of physics and its storehouse of available parts. (Ibid. 1996, 188)

And, further:

Information is inevitably inscribed in a physical medium. It is not an abstract entity. It can be denoted by a hole in a punched card, by the orientation of a nuclear spin, or by the pulses transmitted by a neuron. The quaint notion that information has an existence independent of its physical manifestation is still seriously advocated. This concept, very likely, has its roots in the fact that we were aware of mental information long before we realized that it, too, utilized real physical degrees of freedom. (Ibid. 1999, 64)

This non-typical view of information does not explain or define what information is. Information, whatever it is or whatever its form, always has a material representation. This is necessarily the fundamental nature of information.

In the brain, information takes the form of preferred pathways where behaviour and ideation are considered to be due to synaptic changes in organisation. These changes result from conditioning arising from our sensory and activity experiences, impacting neural network dynamics (Hebb 1949). The human brain becomes an ever-evolving human organ that reflects the physical world in its organisation, but at the same time has the capacity to affect the organisation of the world by the actions of the human being in the act of labour to eke out an existence in and from nature.

Thus, what we would like to explore is a more fundamental approach that not only informs on what information is, but also how it came to be, and even that it is material. The goal is to allow extrapolation and use of the concept of information as a material entity.

\subsection{Definition of Information}

Bateson's definition of information may be viewed as fundamental. It states that: "In fact what we mean by information - the elementary unit of information - is a difference which makes a difference..." (1987/1972, 321). There are two salient characteristics of this definition: One, it implies that information is an elementary unit; and, two, it is self-referential in nature. This definition is attractive due to its simplicity. The implication is that information is subjective and is a self-referential interpretation by human beings of what is of interest to them. It suffices to say that human beings engage in an interactive dialectical process with their environment in gathering information by way of the senses to act on the environment, motivated by the satisfaction of physiological needs (Cárdenas-García 2013; Cárdenas-García and Ireland 2017). Human beings are shaped by material occurrences in the environment - real things and processes - that result from sensory experiences, as well as by their actions in the environment, and the effects of those actions. The resulting learning process historically shapes how we are able to deal with our environment, not only as individuals but also socially.

Further, information is central for all living beings. The analysis and understanding of what information is starts with human beings. Human beings are highly capable of externalisation of their differences, information and ideas. This means that we can now design machines that are capable of detecting and processing information, i.e. "differences that make a difference" to human beings. These machines, however, 
cannot strictly speaking notice "differences that make a difference" to themselves. So, there is no inherent limitation as to the areas in which human beings engage with information, but there are areas in which machines are limited in engaging with information, since they incorporate design limitations. Physical information, biological information and other types of information can be fundamentally viewed from the perspective of "a difference that makes a difference" and are terms that human beings have invented for different reasons.

Hofkirchner (2013b) used this same quote by Bateson to propose its use in a Unified Theory of Information (UTI). It argues for an integrative view that "[...] has to consider both the objective, material, external, and subjective, ideal, internal aspects of information" (Hofkirchner 2013b, 7) and includes subject-object-dialectics.

\subsection{Difference, Information and Idea are Synonymous}

Another notion advanced by Bateson was that, fundamentally, ideas and information are synonymous (1987/1972, 321). So, fundamentally, difference, information and idea are one and the same notion. Cognitively by way of our senses we are able to deal with differences and characterise those differences as ideas that allow us to discern, categorise, describe and share what we learn about our world, orally and otherwise. These ideas can be gesturally and/or orally expressed or, after the development of writing systems, shared by extending our memory into the world using pictographs, sculptures and writing. In short, the differences/information/ideas that take hold or acquire a material representation in the neural circuits of our brain, reflecting the material nature of our world, then find themselves reflected back into our world in multifarious physical forms and actions.

In summary, one advantage of this definition of information is its generality and therefore its applicability to every type of situation in which a human being generates and interacts with information.

\subsection{The Dynamic Nature of Information}

When we identify 'difference/information/idea' what we are really doing is recognising that our natural world is dynamic, a world that reflects differences at every instance of time. This is true in our physical world, as every element of matter or energy in our universe, from smallest to largest, is in perpetual motion above an absolute temperature of zero degrees. Zukerfeld's $(2017,19)$ meticulously described conception of matter/energy is pertinent here, and is summarised by stating "it seems reasonable to speak of what was called 'matter' and energy as a unitary entity" (Ibid.). At the same time, it is important to emphasise that materialist philosophy is at the centre of this discussion. Materialist philosophy sees matter not simply as that which we can touch and feel, but as the totality of systems and substances existing in the world, which includes intangible entities such as ideas (Fuchs 2003; Woods and Grant 1995).

In this milieu, in order for a living being to recognise a difference, two instances of sensory data, i.e., two sensory maps that are spatially and/or temporally separated, are required and must be compared. This is the insight that is missing when quoting Wiener: "Information is information, not matter or energy. No materialism which does not admit this can survive at the present day" (Wiener 1961/1948, 132).

While defining information in terms of itself, Wiener fails to define what information is. Further, he implies that information is not matter or energy. His authoritative stature has never been questioned and is taken as gospel in affirming the ethereal nature of this mysterious information. 
This impossible quandary posed for materialism is fundamentally resolved when it is recognised that our world is dynamic and the senses of all living beings, including humans, cannot but take notice of this material aspect of moving matter/energy. The identification of the difference/information/idea of matter/energy is fundamental to our existence. In short, our universe is only composed of matter/energy, and difference/information/idea is a reflection of the dynamic nature of the universe in the sensory organs of living beings. Matter/energy are fundamental; difference/ information/idea is a derived element only useful to living beings who perceive the dynamic nature of matter/energy. The key element is the process of how these differences/information/ideas impact our lives as they become alienated from us, as is reflective of the Wiener quote.

For human beings, the never-ending sensory map comparisons result in differences/information/ideas that acquire physicality in our brain as adaptable and changing neural networks, leading to further processing and associations that are pertinent to the satisfaction of physiological needs and related learning. This satisfaction of physiological needs and related learning is not a contemplative act, but rather leads to the development of human capabilities that allow successful dialectical interaction with the environment. The material representation in the neural networks in our brain allows this cumulative process to develop during our lifetimes. This cumulative process of noticing differences over time becomes highly complex and discerning.

\section{The Human as a Cognizing Organism-in-its-Environment}

Figure 1 shows a representation of a lone human-individual-in-its-environment, solely with the purpose of illustrating some general characteristics that may be ascribed to this relationship. Note that a differentiation is made, using the Eye of Horus, between "Sensing" and "Ideating". One notable characteristic of this autopoietic homeostatic individual (Maturana and Varela 1980; 1987) is that the dialectical interactions with the environment are not symmetrical. Autopoiesis refers to the quality of organisms of self-production, i.e., that they are continually self-producing so as to maintain their autonomous, homeostatic and unitary integrity (Ibid. 1980; 1987). This unitary autonomous differentiated assembly is inseparable from its surroundings, leading an independent development relative to the planetary environment and an independent dynamic with respect to a corresponding specified established environmental niche. This dialectical organism-in-its-environment uses its senses to interact with the environment in its efforts to satisfy physiological needs, which motivate its actions. 

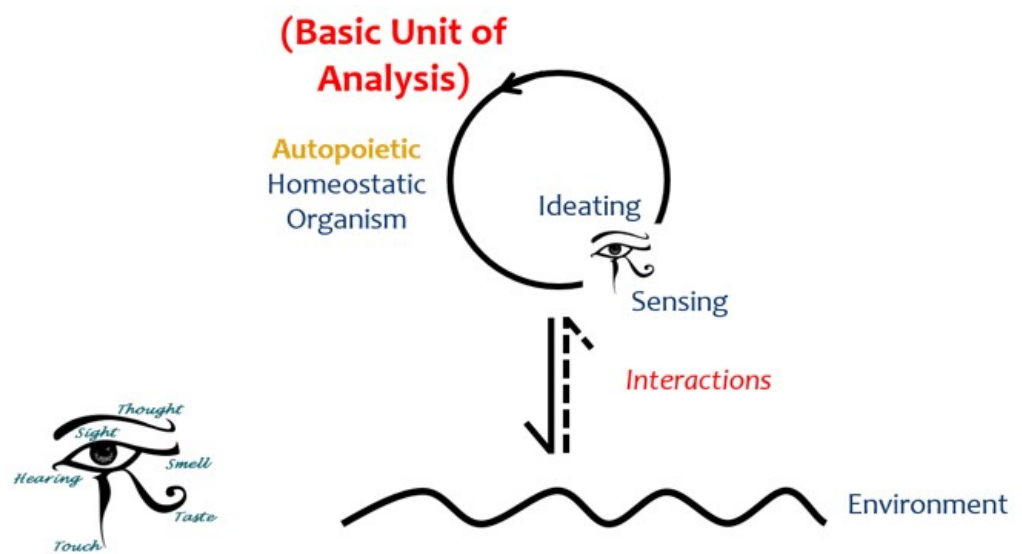

Figure 1: The sensing and ideating autopoietic homeostatic Organism-in-itsEnvironment

Considering only the ontogenetic development of this human organism it is possible to ascribe a 'personal/subjective/relative' view (PSR View) to its behaviour in its initial stages of life and development (Cárdenas-García 2013; Cárdenas-García and Ireland 2017).

As the human organism gains a foothold in the social structure of society, the unavoidable relationship elicited in Figure 2 comes about. It is unavoidable from the first time that a caretaker is involved in the feeding and nurturing of the budding human. Note that for each of the two organisms-in-their-environment the other corresponding organism is just part of the environment, with their corresponding asymmetries in their interactions, both with each other and the other parts of the environment.

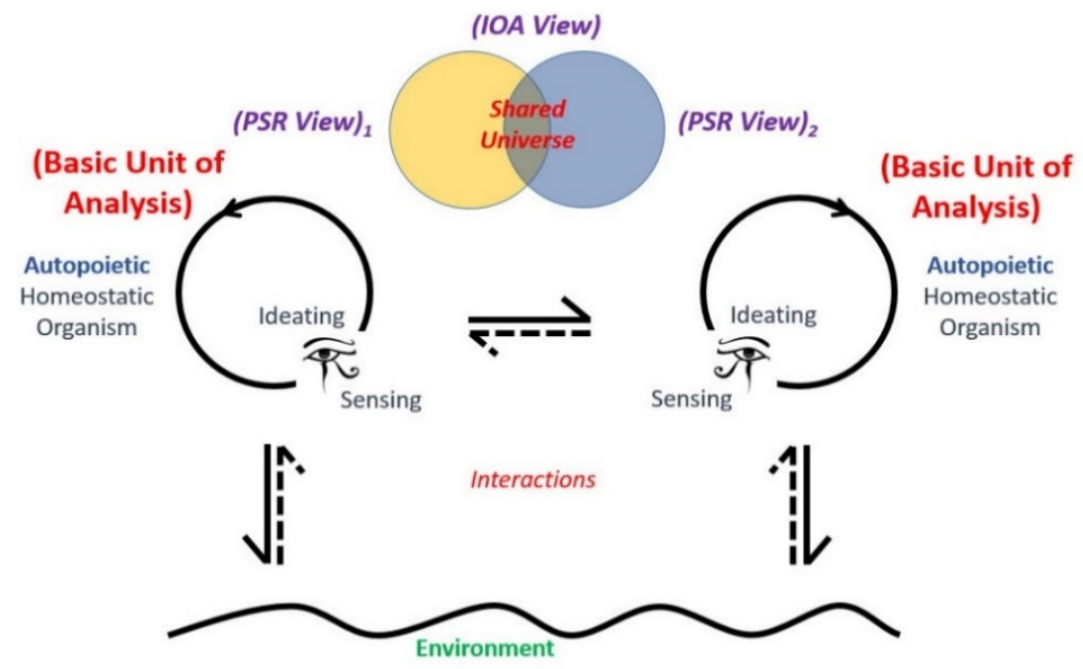

Figure 2: The social sensing and ideating autopoietic homeostatic organism-in-itsenvironment

\subsection{Distributed Cognition}

Each of the human individuals shown in Figure 2 holds a PSR View labelled as (PSR View $)_{1}$ and (PSR View) $)_{2}$, respectively. As a result of the interactions with each other 
and the rest of the environment they are able to develop an 'impersonal/ objective/absolute' view (IOA View). This (IOA View) results from personal experiences that allow each individual to test the limits of personal reality by dialectical interactions with its environment, and by social dialectical interactions that result in a consensual "Shared Universe" (Cárdenas-García 2013; Cárdenas-García and Ireland 2017).

The unavoidable interactions of the human organism with the environment result in a (PSR View) and an (IOA View) that are immanent to the human organism. The human organism interactions with the environment rely on differences/information/ ideas in a never-ending process of distributed cognition ever since the human organism started life as a single cell. These interactions lead to corresponding spaces of PSR Information/Ideas and IOA Information/Ideas. The mature human organism out of the womb is dependent on its five senses to register differences/information/ideas in this process of distributed cognition. One of the most ignored aspects of information is the recognition that human beings are at the centre of all information recognition, extraction, creation, transmission, preservation, storage and utilisation. This process of information-gathering is initially a PSR Information/Ideas gathering process that interacts with the IOA Information/Ideas gathering process as the human organism explores its reality. Key to this exploration are the sensory organs which also correspond to the motility capabilities that the human organism develops, as it sharpens its capacity for effective dialectical interaction with its environment, in pursuit of satisfaction of its physiological and social needs.

\subsection{Concrete Totality}

All of these interactions in search of reality can be ascribed within the scope of "Concrete Totality" (Kosik 1969), or a dialectical materialist conception of reality, "reality as a concrete totality (as a whole structure in the process of development and self-creation)" (Ibid.).

Figure 3 shows a conceptualisation of "Concrete Totality" as an ascending ladder of dialectical triangles. Each of the dialectical triangles reflects the basic premise that a human organism, in acquiring PSR Information/Ideas (Subject), is also interacting with its environment and acquiring IOA Information/ldeas (Object). The result is the dialectical unity of PSR Information/Ideas - IOA Information/Ideas (Subject-Object).

The lowest dialectical triangle in Figure 3 shows a human Organism (Subject) interacting with its Environment (Object). The result is the beginning of Ideation (Subject-Object), or (PSR Ideas) $)_{0}$. (PSR Ideas) $)_{0}$ are an accumulation of ideas relevant to the human organism for the most basic level of cognition. This first stage may be characterised ontogenetically as the stage in which young humans are viewed as defenceless in their ability to deal with the world. They only have access to an inward-looking perspective, without the capability for interacting with the environment, except in the form of reflex actions. 


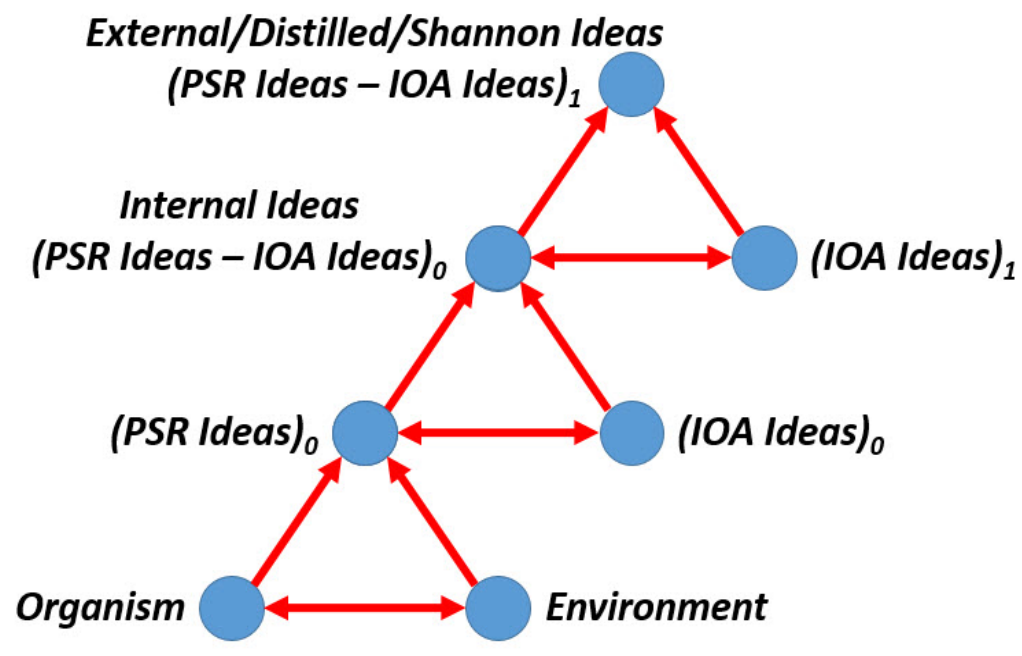

Figure 3: The realisation of "Concrete Totality"

\subsection{Internal Information}

The middle dialectical triangle in Figure 3 further shows the ontogenetic process where the human organism starts out with (PSR Ideas) $)_{0}$ and engages with its Environment in an interactive process while acquiring greater dexterity to gain (IOA Ideas) $)_{0}$. This stage results in the generation of Internal Ideas (PSR Ideas - IOA Ideas) $)_{0}$. The capability for having Internal Ideas is relevant to the development of the ability to manipulate ideas in the human brain and to develop a rich internal life. The human organism at this stage is incapable of understanding the separation between itself and the environment. As such, it is not capable of understanding its own existence and its own history of past, present and future. This stage is superseded when the human organism is capable of rudimentary language use and/or rudimentary tool use.

\subsection{External, Distilled or Shannon Information}

The top dialectical triangle in Figure 3 goes to the heart of the concept of distributed cognition or the immanent dialectical relationship between life and information. Distributed cognition is the ability of a self-referencing organism to interact with its environment for the purpose of satisfying its physiological (internal and external) and social needs to survive and sustain itself (Cárdenas-García 2013; Cárdenas-García and Ireland 2017). It is in this stage, after we develop language, that most of our creative life takes place.

Understanding of the separation of the human organism from the subsuming environment eventually emerges due to the process of human socialisation that begins between the caretaker and the young child. This process of distributed cognition accelerates and refines this PSR and IOA Information/Ideas-gathering and dialectical process in the human child. The development of IOA Information/Ideas helps to further the consensual spaces between human children and adults: these spaces assist in their collaborative activities and result in the furthering of common objectives such as the pursuit of independence, understanding and language.

Thus, in this preliminary process in the life of a child, the child evolves from a state in which he is incapable of knowing that his existence is separate from his environment - where any expression of being hungry, tired or physically uncomfortable is just a reaction to bodily urges, without meaning - to that in which 
the separation is more distinct, and a greater awareness of his predicament when hungry, tired or physically uncomfortable gives way to signs, gestures and sounds so that he can make himself understood: a process that evolves from a state of Internal Information to a state of External or Distilled Information, where the resulting PSR Information/Ideas - IOA Information/Ideas dialectic can be externalised or distilled. The externalisation or distillation of Information/Ideas with other human beings, in the social setting of which it is a part, acquires meaning due to the created developing consensual spaces.

\subsection{Human Speech and Language}

The formal historical expression of this PSR Information/Ideas-IOA Information/Ideas dialectic as External/Distilled Information/ldeas is in the form of wall paintings, ancient stone artefacts, sculptures and musical instruments. The culmination of this process in antiquity is the origination of human speech and language. Human speech and language are the ultimate tools tied directly to Distilled Information. Orality in humans has a long history (which even today is present around the world) revealing the highly-developed skills that can be harnessed in its pursuit and the ways in which orality can be used as a storehouse of cultural traditions that can be passed down from generation to generation: each generation adding its own experiences as it honours what came before it. This cultural production of Distilled Information is fully dependent on a continuous line of practitioners of orality, vulnerable to disruption.

\subsection{Written Language}

This process of External/Distilled Information generation leads to what may be regarded as the ultimate tool: writing implements. This momentous event is significant because it ties together for the first time tools that allow a more permanent existence to External/Distilled Information. The development of writing begins with the practical need for more permanent accounting practices in Mesopotamia in the fourth millennium BC, evolving from simple pictographs towards more structured signs representing word sounds. The significance of writing is that it provides a more permanent expression of External/Distilled Information. This is achieved by putting a tool between the originator of the External/Distilled Information or writer and the medium of expression on which that writing implement is used. The writing implement serves as an extension of the writer to directly mould nature to his will. This separation of the writer from the medium of impression and expression has the potential to dispossess the writer from his labour, i.e., from his creation of an original. But the writing process uniquely characterises the expression of the talent of the writer. This is a tie between the writer and his work that is difficult to erase, and it represents the talent of writing with unique personal characteristics. In most instances, the medium that is used for writing is destructible, entailing the possible end of the External/Distilled Information. It is also possible that the medium lasts longer than the lifetime of its originator. In this case, the sharing of the written information remains a possibility only if the code associated with the writing is shared over time.

These characteristics had not been true of oral expression, since whoever was in possession of the oral content that was to be expressed had artistic control both of the form and content of that expression. And that act of oral expression was delivered directly to whatever audience was present to consume the oral performance. The end of the performance was the end of the External/Distilled Information. In short, the invention of writing was a qualitative leap for humankind in 
promoting the permanence of External/Distilled Information. Classical writings could be accumulated, critiqued and enhanced over many generations and contemporary cultures.

\subsection{Printed Language}

The next step in the development of writing is the printing press, where an original work is submitted to a printer for reproduction. This allows the proliferation of originals, due to lower production costs, but further disinherits the writer of the credit of the original. In a few cases, it might allow the printer to pay the writer for her efforts and make a profit from the printing run. The printing press makes the final product one of many copies with no sign of the writer or the printer if not contained somewhere in the text. The quasi-permanence of print media limits the manipulation of its content.

\subsection{The Origin of Shannon Information}

The discovery of electromagnetism and the electromagnetic spectrum brought about the next technological developments, which allowed by analogic means the reproduction of the human voice and its transmission through the airwaves. So once again it was possible for oral expression to take prominence through original productions that were either generated in real-time or read from written texts, and even recorded in analogue media for repeated consumption. However, use and/or manipulation of the recorded information was limited.

It is only with the advent of the need to improve the efficiency, precision and reach of oral and written communication that the field of Information and Information Theory gained impetus. This occurred prior to, during and after the Second World War with the work of Fisher (1935), Gabor (1946), Wiener (1961/1948) and Shannon (1948), culminating in the First International Symposium on Information Theory, held in London in the summer of 1950. Shannon was a key player in the field who promoted the connection between Boolean algebra and electronic circuits (1938). His efforts resulted in the digital revolution of which we are now a part. These events led to the ultimate transformation of Distilled information into binary digits, or bits, that are capable of being processed in electronic digital machines, thus enabling the storage, processing and transformation of Distilled Information from the heads of its creators into machines; machines that have become our companions in their different embodiments. This type of information may be labelled Shannon Information.

In summary, human beings are at the centre of all information recognition, extraction, creation, transmission, preservation, storage and utilisation. Over time, the limits to these human-centric information activities have receded. What began as PSR-Information/Ideas evolved to IOA-Information/Ideas and human Ideation, leading to language, pictographs, sculptures, music and writing as expressions of the Externalisation/Distillation of these Information/Ideas. This outcome is referred to as Externalised/Distilled Information/Ideas. Further historical development has led to technological developments that allow the Externalised/Distilled/Shannon Information/ldeas to be captured in analogue and digital machines, whether in oral or written form, for ease of manipulation and transmission for the benefit of humankind. This current centrality of Shannon Information has done little to change the notion of information/ideas from being ethereal/immaterial to being material. It also obscures the centrality of human beings in the process of Information/ldeas, and mystifies the relationship between information/ideas and labour. 


\section{Labour}

The fundamental premise for labour is best summarised by Engels:

LABOUR is the source of all wealth, the economists assert. It is this next to nature, which supplies it with the material that it converts into wealth. But it is also infinitely more than this. It is the primary basic condition for all human existence, and this to such an extent that, in a sense, we have to say that labour created man himself. (Marx and Engels 1987, 452)

And elaborated on by Marx:

Labour, then, as the creator of use-values, as useful labour, is a condition of human existence which is independent of all forms of society; it is an eternal natural necessity which mediates the metabolism between man and nature, and therefore human life itself.

Use-values like coats, linen, etc., in short, the physical bodies of commodities, are combinations of two elements, the material provided by nature, and labour. (Marx 1976/1867, 47)

Further,

The mystical character of the commodity does not therefore arise from its use-value. Just as little does it proceed from the nature of the determinants of value. For in the first place, however varied the useful kinds of labour, or productive activities, it is a physiological fact that they are functions of the human organism, and that each such function, whatever may be its nature or its form, is essentially the expenditure of human brain, nerves, muscles and sense organs. Secondly, with regard to the foundation of the quantitative determination of value, namely the duration of that expenditure or the quantity of labour, this is quite palpably different from its quality. In all situations, the labour-time it costs to produce the means of subsistence must necessarily concern mankind, although not to the same degree at different stages of development. And finally, as soon as men start to work for each other in any way, their labour also assumes a social form. (lbid., 55)

These statements (boldface added for emphasis) summarise the fundamental aspects of the relationship between human beings and nature. Indeed, the immanent dialectical relationship between human beings and nature is the basis for our historical development. This also brings into focus the corresponding dialectical relationship between our senses and our motility in the environment, leading to Information/Ideas and subsequent PSR and IOA Views, and the role that these have played in the development of humankind. 


\subsection{The Labour-Object-Product of Labour Process}

Fundamental to all of this is "the expenditure of human brain, nerves, muscles and sense organs" (Marx 1976/1867, 55); in other words, human labour. Figures 4(a) and 4(b) show an ascending-ladder qualitative representation and an ascending-ladder quantitative representation, respectively, of the vertically integrated Labour-ObjectProduct of Labour Process.

The left part of the diagram in Figure 4(a) shows various levels of (Labour Power $)_{0=>4}$ to indicate that human labour is very much dependent on historical individual physical human capabilities which, besides muscular traits, include those related to the developing central nervous system, including sensory organs. The right part of the same diagram shows, beginning at the bottom with Nature represented by the term Natural Resources, the ascendant nature of the corresponding (Products of Labour $)_{0=>4}$ or commodities as a result of the development of capitalism. These labels have been chosen in an attempt at the qualitative generalisation of labour and its products.

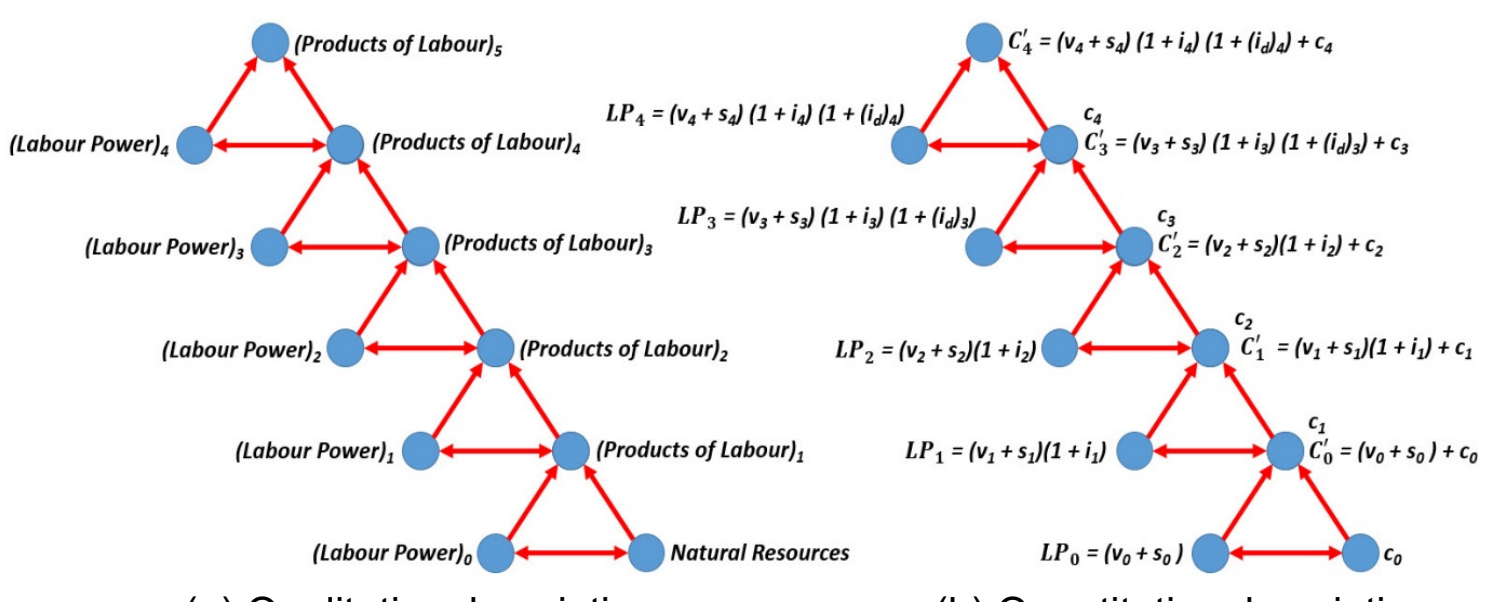

(a) Qualitative description

(b) Quantitative description

Figure 4: The Labour-Object-Product of Labour Process

The dialectical triangle at the bottom of the ladder in Figure 4(a) portrays the initial relationship of humans with Natural Resources, resulting in the first products of labour that have a direct correspondence with use-values. The rest of the dialectical ladder may be likened to the current phase of capitalism, which can incorporate very complex modes of interaction between developing human labour power and corresponding products of labour. Each of these triangles incorporate the elementary factors of the labour-process: the labour expended by a human being; the object on which that human labour is expended; and, the instruments of labour that may act as intermediaries between the human being and the object of labour. This is illustrated as follows:

A product, though ready for immediate consumption, may nevertheless serve as raw material for a further product, as grapes do when they become the raw material for wine. On the other hand, labour may release its product in such a form that it can only be used as raw material. Raw material in this condition, such as cotton, thread and yarn, is called semi-manufactured, but should rather be 
described as having been manufactured up to a certain level. Although itself already a product, this raw material may have to go through a whole series of different processes, and in each of these it serves as raw material, changing its shape constantly, until it is precipitated from the last process of the series in finished form, either as means of subsistence or as instrument of labour.

Hence we see that whether a use-value is to be regarded as raw material, as instrument of labour or as product is determined entirely by its specific function in the labour process, by the position it occupies there: as its position changes, so do its determining characteristics. (Marx 1976/1867, 127)

The labour power at each level needs to be understood in terms of "expenditure of human brain, nerves, muscles and sense organs" (Ibid., 55). The (Products of Labour) with which each level of (Labour Power) interacts have to correspond to each other in order to yield a higher level of (Products of Labour). Labour power is intrinsic to human beings, as they eke out a living from nature from their beginnings, always employing the necessary elements intrinsic to unique individual human beings when such exertion of labour power is required. Historically, physical labour, when broken down to its basic elements, is often seen as homogeneous when different individuals perform the same tasks. There is no concern for individual experiences (PSR/IOA Views). There is only concern for the physical exertion that might be extracted from each (unique) individual. The capitalist is unconcerned about the intellectual or physical makeup of the humans it hires, just so long as the person hired meets the minimal requirements for the job at hand, leaving room for on-the-job training.

\subsection{The Labour-Object-Product of Labour Process in the Information Age}

If the process is examined more closely we should not be concerned too much with what the capitalist requires of the human labourer. Rather, we should be concerned with what is actually happening in the process of creation of qualitative use-values and quantitative values as fruits of labour from the perspective of the human labourer.

First, let's concern ourselves with the creation of qualitative use-values. The process of labour as "expenditure of human brain, nerves, muscles and sense organs" (Marx 1976/1867, 55) implies that humans, at the same time that they exert their labour power, are also processing information as living beings, i.e. they are detecting "differences that make a difference" (Bateson 1987/1972, 321). For example, if a labourer is working in a mine, she is using the tools at her disposal with prior knowledge related to her skill as a labourer. She is not only recognising environmental information to ease the strain and promote the efficiency of mining, but also imparting information on the raw materials that are the object of her efforts. The imparting of information can be as simple as knowing how to stack and size raw materials for ease of transport.

In time, the skill of a labourer is easily definable and recognisable. There is information to be gleaned from the motions of the labourer and from the resulting product of the labourer. Creation of qualitative use-values reflect the informational aspects of the labour process. Consider the example of a tool such as a spoon. The associated use-value may relate to ladling hot soup from a bowl to our mouths 
instead of using our hands. We value the spoon for its unique use-value, which is reflected by its design and the process used to implement its construction. Concrete qualitative useful labour produces use-values subject to individual needs that arise from subjective, self-referenced information. Further, it is unimportant whether the spoon is made of wood or of a precious metal as far as its use-value is concerned. The concrete information content of either spoon is considered to be the same: both serve the useful role of ladling soup into our mouths. There is a dialectical parallel alignment of the qualitative characteristics of information and concrete useful labour.

A second consideration that this example of a side-by-side comparison of a wooden and a precious metal spoon warrants is that of quantitative value. There is another "difference that makes a difference" that bears on a quantitative comparison. This other consideration of information is revelatory of a difference in the lesser abstract labour-time required to manufacture the wooden spoon, as compared with the precious metal spoon. The congealed labour-time is shown to yield different intrinsic qualities to the spoons, e.g. 'dull, unattractive' and 'shiny, attractive' spoon surfaces, respectively, for one. For qualities that are quantifiable by measurements such as surface roughness or reflectivity, once again, there is a dialectical parallel alignment of the quantitative characteristics of information and abstract labour.

In short, there is an immanent and indissoluble relationship between information and labour. Concrete useful labour yields information relevant to use-value. Abstract labour-time yields information relevant to value. Information impacts the labour process qualitatively and quantitatively, and vice versa.

Figure 4(b) shows an effort to quantify these aspects of production using a similar hierarchical dialectical ladder as before. The lowest rung of this ladder reflects the typical Marxist perspective of the labour theory of value. It shows that a human being exerts the requisite (Labour Power $)_{0}$ or (LP) $)_{0}$, composed of 'necessary' labour time under the guise of variable capital, $\mathrm{v}_{0}$; and surplus labour time, $\mathrm{s}_{0}$, the labour that the worker produces above 'necessary' labour time and donates to the capitalist as surplus labour or surplus value, due to his condition as a labour-time commodity producer. When this (LP) $)_{0}$ is added to the fixed capital, $\mathrm{c}_{0}$, composed of the means of production, it results in the final capital that accrues to the capitalist once all of the product has been sold in the marketplace. This is the process in which the initial capital $\mathrm{C}_{0}=\mathrm{v}_{0}+\mathrm{C}_{0}$ is transformed in the capitalist production process, as if by magic, into final capital $C_{0}^{\prime}=\left(v_{0}+s_{0}\right)+c_{0}$. The difference between these two stages of capital production results in the surplus value, $\mathrm{s}_{0}$. There is typically no concern for incorporation of 'informational content' and 'cultural content' in the production of commodities.

Explanations such as that found in Sandoval et al. (2014) emphasise the character of the product in explaining how information labour and digital labour are included in the labour process:

The working lives of Muhanga, Lu, Bopha, Mohan, Bob, and Ann seem completely different. Muhanga extracts minerals from nature. $\mathrm{Lu}$ and Bopha are industrial workers. Mohan, Bob and Ann are information workers creating either software or designs. They work under different conditions, such as slavery, wage labour, or freelancing. Yet they have in common that their labour is in different ways related to the production and use of 
digital technologies and that ICT companies profit from it.

(lbid., 487)

Also, these explanations consider as inherent any relevant cognitional/ informational elements in the labour process.

The second and third ladder rungs from the bottom in Figure 4(b) are used to illustrate how cognitional/informational elements may be made explicit in the labour process. This would be considered typical of the efforts exerted by Muhanga, Lu and Bopha in a production process typical of the industrial age. Their labour power consists, as before for the second ladder rung, of requisite (Labour Power) $)_{1}$ or $(L P)_{1}$, composed of paid labour time or variable capital, $v_{1}$, and unpaid labour time or surplus value, $s_{1}$, i.e., $(L P)_{1}=\left(v_{1}+s_{1}\right)$ as before. To account for information labour as an additional element, we define this additional information labour as the product of $\dot{i}_{1}$ and $\left(v_{1}+s_{1}\right)$, where $i_{1}$ is the fraction of $(L P)_{1}$ that may be ascribed to informational labour. (LP $)_{1}$ is taken as the reference for the added information labour. Typical values for $i_{1}$ could vary from 0 to 1 . Therefore, the total labour power is given by $\left(v_{1}+\right.$ $\left.s_{1}\right)\left(1+i_{1}\right)$. In short, information labour is necessarily connected to paid labour time and unpaid labour time. Elements of concrete information labour (related to useful labour) and abstract information labour (related to time) may be identified. Information labour, as an immanent component of labour power, is congealed into the final product and is inseparable from the final product, as are 'necessary' labour time and surplus labour time. It is an additional, explicit element of dead labour. By this process, the initial capital $\mathrm{C}_{1}=\mathrm{v}_{1}+\mathrm{C}_{1}$ is transformed in the capitalist production process, as if by magic, into final capital $C_{1}^{\prime}=\left(v_{1}+s_{1}\right)\left(1+i_{1}\right)+c_{1}$. The difference between these two stages of capital production results in surplus value, $s_{1}\left(1+i_{1}\right)$, of the commodity. In the eyes of the capitalist, surplus information value is as unrecognisable as is surplus value. Consider that whether you choose to stay an extra hour at work to help the capitalist in a crunch, or whether you are more diligent in looking out for the quality of a product, by imparting information by quantifiable actions, the net gain to your livelihood is zero. Note also that the rate of surplus value, given by $s_{1}\left(1+i_{1}\right) / v_{1}$, and the rate of profit, given by $s_{1}\left(1+i_{1}\right) /\left(c_{1}+v_{1}\right)$, increase just by the fact of adding information labour content that goes unrecognised. Information labour may be viewed from a practical perspective as that extra element in the labour process that results from caring about a job well done, on-the-job experience and additional education that, consciously or unconsciously, is reflected in the labour process. Of course, if you are not feeling well on any given day of the work week your information labour may suffer, to the detriment of the capitalist.

The fourth and fifth ladder rungs from the bottom in Figure 4(b) are reflective of the work of Mohan, Bob and Ann in their typical workplace in the information age. Their labour power consists, for the fourth ladder rung, of requisite (Labour Power) ${ }_{3}$ or $(\mathrm{LP})_{3}$, composed of paid labour time or variable capital, $v_{3}$, unpaid labour time or surplus value, $s_{3}$, and information labour $i_{3}\left(v_{3}+s_{3}\right)$, i.e., $(L P)_{3}=\left(v_{3}+s_{3}\right)\left(1+i_{3}\right)$. To account for the new element of digital information labour, we define digital information labour as the product of $\left(i_{d}\right)_{3}$ and $\left(v_{3}+s_{3}\right)\left(1+i_{3}\right)$, where $\left(i_{d}\right)_{3}$ is the fraction of $(\mathrm{LP})_{3}$ that we ascribe to digital information labour. As before, the values for $\left(i_{d}\right)_{3}$ range from 0 to 1 . We choose to define digital information labour in this fashion under the assumption that the digitisation process is an extra step in the labour process that subsumes paid labour, surplus labour and information labour. Digital information labour consists of concrete digital information labour (related to useful labour) and abstract digital information labour (related to time). Digital information labour, as another immanent component of labour power, is congealed into the final 
product, but is found to be separable from the final product. In this sense, it is different from 'necessary' labour time, surplus labour time and information labour. It is another additional and explicit element of virtual live labour. By this process, the initial capital $\mathrm{C}_{3}=\mathrm{v}_{3}+\mathrm{C}_{3}$ is transformed in the capitalist production process, as if by magic, into final capital $C_{3}^{\prime}=\left(v_{3}+s_{3}\right)\left(1+i_{3}\right)\left(1+\left(i_{d}\right)_{3}\right)+c_{3}$. The difference between these two stages of capital production results in the surplus value, surplus information value and surplus digital information value, $s_{3}\left(1+i_{3}\right)\left(1+\left(i_{d}\right)_{3}\right)$, of the commodity. Surplus digital information value is as unrecognisable as are surplus value and surplus information value in the eyes of the capitalist. Surplus digital information value is virtual live labour, because it is labour that can be sold at a later time, because it is owned by the capitalist, and even resurrected and repurposed by the capitalist at will at some time in the future. It is as if the capitalist is finally able to own the labourer, without physically enslaving her, or the labourer knowing or caring. Note also that the rate of surplus value, in this case given by $s_{3}\left(1+i_{3}\right)\left(1+\left(i_{d}\right)_{3}\right) / v_{3}$, and the rate of profit, given by $s_{3}\left(1+i_{3}\right)\left(1+\left(i_{d}\right)_{3}\right) /\left(c_{3}+v_{3}\right)$, increase just by the fact of adding that additional element of digital information labour content. This added insight may serve as a stepping stone into an enquiry into the role of information in culture, since cultural development is necessarily tied to human labour.

In summary, these products of the information age differ from the products of earlier eras in a more fundamental way. These digital products not only produce surplus value that accrues to the capitalist in the form of dead labour, akin to that of industrial-era products, but the digital content in these products is owned by the capitalist and may be likened to virtual living labour. The capture of digital content is akin to capturing the artist/labourer in digitised form. The artist/labourer has then lost control of her creative product, which can be brought back to life at will by the capitalist. This dynamic is true of Internet interactions (Google, Facebook, YouTube, Twitter, etc.) as well as other products such as designs, books, compositions, movies, and so on. So not only does the capitalist benefit from surplus labour, but the capitalist is able to accumulate virtual living labour as part of her stock of capital. The result is greater exploitation of the labour force, not only during the duration of the labour process, but over a longer-term horizon dictated by the capitalist. In this scheme, alienation acquires a new meaning since the labourer does not even realise that his labour continues to exist for the capitalist.

This same perspective may be taken with regard to robotic creations where, once built and programmed by human beings, a robot can repeat its operations as many times as needed to perform repetitive labour operations that no human worker could match. The benefit to the capitalist is a reduction in the number of workers needed to perform the work of many more human workers. The growing pool of the unemployed, where labourers have no recourse to the labour market, appears inevitable. They are collateral damage to the accumulation of virtual living labour by the capitalist.

\section{Summary and Conclusions}

This work attempts to put in perspective the information age on the basis of the fundamental concept of information and the current associated digitisation process. This process impacts all aspects of our lives in realising the material basis of information, i.e., that information/ideas are material. This serves to reveal that even though we are increasingly dependent on information as a resource to the capitalist productive process, the importance of human labour in the process is undiminished, including its role in the generation of surplus value. This fundamental approach 
serves to discard the concept of immaterial labour and products, and digital labour. It also reaffirms an undeniable materialist basis for the labour theory of value, where information plays an important role. Indeed, there is an undeniable immanence between information and labour, leading to uncovering the role of information during and before the industrial age, as well as now, at the beginning of the information age. This novel perspective applied to the labour theory of value leaves no illusions as to the exploitative and alienating characteristics of present-day capitalism.

\section{References}

Arendt, Hannah. 1998. The Human Condition [2nd Edition]. Chicago: Chicago University Press.

Bateson, Gregory. 1987/1972. Steps to an Ecology of Mind. Northvale, NJ: Jason Aronson Inc.

Burston, Jonathan, Nick Dyer-Witheford, and Alison Hearn. 2010. Digital Labour: Workers, Authors, Citizens. Ephemera: Special issue 10 (3-4): 214-539.

Cárdenas-García, Jaime F. 2013. Distributed Cognition: An Ectoderm-Centric Perspective. Biosemiotics 6 (3): 337-350.

Cárdenas-García, Jaime F. and Timothy Ireland. 2017. Human Distributed Cognition from an Organism-in-its-Environment Perspective. Biosemiotics 1-14. DOI: 10.1007/s12304017-9293-8.

Castells, Manuel. 2009. Communication Power. New York: Oxford University Press.

Fisher, Ronald A. 1935. The Design of Experiments. London: Oliver and Boyd.

Fuchs, Christian. 2016. Critical Theory of Communication. London: University of Westminster Press.

Fuchs, Christian. 2014. Digital Labour and Karl Marx. New York: Routledge.

Fuchs, Christian. 2012. Dallas Smythe Today: The Audience Commodity, the Digital Labour Debate, Marxist Political Economy and Critical Theory. Prolegomena to a Digital Labour Theory of Value. tripleC: Communication, Capitalism \& Critique. Open Access Journal for a Global Sustainable Information Society. 10 (2): 692-740.

Fuchs, Christian. 2003. The Self-Organization of Matter. Nature, Society, and Thought 16 (3): 281-313.

Fuchs, Christian and Vincent Mosco. 2012. Marx is Back. The Importance of Marxist Theory and Research for Critical Communication Studies Today. tripleC: Communication, Capitalism \& Critique. Open Access Journal for a Global Sustainable Information Society. 10 (2): 127-632.

Fuchs, Christian and Sebastian Sevignani. 2013. What is Digital Labour? What is Digital Work? What's their Difference? And Why Do These Questions Matter for Understanding Social Media? tripleC: Communication, Capitalism \& Critique. Open Access Journal for a Global Sustainable Information Society. 11 (2): 237-293.

Gabor, Dennis. 1946. Theory of Communication. Journal of the Institution of Electrical Engineers 93: 429-460.

Hardt, Michael, and Antonio Negri. 2000. Empire. Cambridge, MA: Harvard University Press.

Hebb, Donald O. 1949. The Organization of Behavior: A Neuropsychological Theory. New York: John Wiley \& Sons Inc.

Hofkirchner, Wolfgang. 2013a. Emergent Information. When a Difference Makes a Difference... tripleC: Communication, Capitalism \& Critique. Open Access Journal for a Global Sustainable Information Society. 11(1): 6-12.

Hofkirchner, Wolfgang. 2013b. Part 1: Towards a Science of Information. In Emergent Information: A Unified Theory of Information Framework, edited by Wolfgang Hofkirchner, 3-34. Singapore: World Scientific Publishing.

Jappe, Anselm. 2013. Contro il Dentro. Milan: Mimesis.

Kosik, Karel. 1969. The Concrete Totality. Telos 4: 35-54. 
Landauer, Rolf. 1999. Information is a Physical Entity. Physica A: Statistical Mechanics and its Applications 263: 63-67.

Landauer, Rolf. 1996. The physical nature of information. Physics letters A, 217 4-5: 188193.

Landauer, Rolf. 1991. Information is Physical. Physics Today 44 (5): 23-29.

Lazzarato, Maurizio. 1996. Immaterial Labor. In Radical Thought in Italy: A Potential Politics, edited by Paolo Virno and Michael Hardt, 133-148. Minneapolis: University of Minnesota Press.

Marx, Karl. 1976/1867. Capital: A Critique of Political Economy. London: Penguin Books.

Marx, Karl, and Friedrich Engels. 1987. Collected Works: Anti-Dühring, Dialectics of Nature (Volume 25). London: Lawrence and Wishart.

Maturana, Humberto, and Francisco J. Varela. 1987. The Tree of Knowledge: The Biological Roots of Human Understanding. Boston, MA: Shambhala Publications.

Maturana, Humberto, and Francisco J. Varela. 1980. Autopoiesis and Cognition. Dordrecht: Reidel.

Mosco, Vincent. 2009. The Political Economy of Communication. 2nd Ed. Los Angeles: SAGE Publications.

Roos, Andreas, Vasilis Kostakis and Christos Giotitsas, eds. 2016. The Materiality of the Immaterial: ICTs and the Digital Commons. tripleC: Communication, Capitalism \& Critique. Open Access Journal for a Global Sustainable Information Society. 14 (1): 48162.

Sandoval, Marisol, Christian Fuchs, Jernej A. Prodnik, Sebastian Sevignani and Thomas Allmer. 2014. Philosophers of the World Unite! Theorising Digital Labour and Virtual Work: Definitions, Forms and Transformations. tripleC: Communication, Capitalism \& Critique. Open Access Journal for a Global Sustainable Information Society. 12 (2): 464-801.

Scholz, Trebor, ed. 2013. Digital Labor: The Internet as Playground and Factory. New York: Routledge.

Shannon, Claude E. 1948. A Mathematical Theory of Communication. The Bell System Technical Journal 27: 379-423; 623-656.

Shannon, Claude E. 1938. A Symbolic Analysis of Relay and Switching Circuits. Transactions American Institute of Electrical Engineers 57: 713-723.

Shannon, Claude E., and Warren Weaver. 1949. The Mathematical Theory of Communication. Urbana, IL: The University of Illinois Press.

Smythe, Dallas W. 1977. Communications: Blindspot of Western Marxism. Canadian Journal of Political and Social Theory/Revue Canadienne de Theorie Politique et Sociale 1 (3): 127.

Virno, Paolo, and Michael Hardt, eds. 1996. Radical Thought in Italy: A Potential Politics. Minneapolis: The University of Minnesota Press.

Wiener, Norbert. 1961/1948. Cybernetics or Communication and Control in the Animal and the Machine. Cambridge, MA: MIT Press.

Woods, Alan and Ted Grant. 1995. Reason in Revolt: Marxist Philosophy and Modern Science. New York: Algora.

Zukerfeld, Mariano. 2017. Knowledge in the Age of Digital Capitalism. London: University of Westminster Press.

\section{About the Authors}

Jaime F. Cárdenas-García

Jaime F. Cárdenas-García is a Visiting Research Scientist in the Department of Mechanical Engineering at the University of Maryland - Baltimore County. He obtained his BSME, MS and $\mathrm{PhD}$ degrees from the University of Maryland in College Park. 


\section{Bruno Soria de Mesa}

Bruno Soria De Mesa is a Member of the Faculty in the area of Health and Society in the Medical School of the Escuela Superior Politécnica de Chimborazo (ESPOCH) in Riobamba, Ecuador, as well as a member of the Publications Committee. He obtained his Master in Governance and Development, and his Doctorate in Sociology and Political Science degrees at the Universidad Central del Ecuador in Quito.

\section{Diego Romero Castro}

Diego Romero Castro is Assistant Professor in the Faculty of Jurisprudence and Social and Political Sciences at the Universidad de Guayaquil, Ecuador, specifically in the areas of Latin American Integration and Administrative Law. He is a lawyer, with a Master in Applied Political Studies and a Master in Fundamental Rights and Constitutional Justice, degrees granted in Ecuador and Spain, respectively. He is currently doing research in the areas of Justice of Peace and New Rights. 